\title{
MANAGING LANDSCAPES FOR CONSERVATION UNDER UNCERTAINTY
}

\author{
M. A. Burgman, ${ }^{1,3}$ D. B. Lindenmayer, ${ }^{2}$ And J. Elith ${ }^{1}$ \\ ${ }^{1}$ School of Botany, University of Melbourne, Parkville 3010 Australia \\ ${ }^{2}$ Centre for Resource and Environmental Studies, Australian National University, ACT 0200 Australia
}

\begin{abstract}
In ecology, populations may be linked conceptually with landscapes through habitat and spatial population models. Usually, these models deal with single species and treat a range of uncertainties implicitly and explicitly. They assist managers in testing different management scenarios and making strategic decisions. Landscape pattern analysis was the first attempt to deal with multiple species, and it led to a range of landscape management strategies. Advances in landscape ecology, driven largely by the pragmatic needs of conservation, are building approaches to multispecies management that have stronger ecological foundations. However, their treatment of uncertainty is in its infancy. In this paper, we provide examples to illustrate some of these issues. We conclude that one of the most important sources of uncertainty is the choice of the modeling frame. We recommend that landscape planners use different kinds of models, identify important sources of uncertainty that may affect planning decisions, and seek options that are likely to result in tolerable outcomes, despite uncertainty.
\end{abstract}

Key words: decision theory; focal species; habitat maps; landscape ecology; metapopulations; nested subsets; reserve design; spatial pattern.

\section{INTRODUCTION}

Habitat loss causes losses of biodiversity worldwide (Fahrig 2003, Hobbs and Yates 2003). Forman (1995, Forman and Godron 1986) sparked conservation interest in landscape ecology by predicting that species and ecological systems may be conserved by managing landscape-scale patterns and processes. Hanski and Gilpin (1991) predicted the merger of ideas in landscape ecology, community ecology, and metapopulation theory. A synthesis has not yet occurred, in part because they employ different jargon and use different analytical tools (Moilanen and Hanski 2001). In fact, perspectives have become more divergent. The range of tools has multiplied without a critical evaluation of their role in the broader context of making decisions to conserve landscapes.

The objectives of this paper are to outline approaches to modeling in landscape ecology, to document their uncertainties, and to evaluate ways of using them to make decisions under uncertainty. In particular, we will point towards new developments that might improve the ways in which uncertainty is acknowledged and included in decision making. This topic is important because unacknowledged uncertainty leads to optimistic expectations that cannot be satisfied, to the misdirection of scarce conservation resources, and to actions that are blind to substantial qualitative and quantitative uncertainties that, if they were apparent, would lead to different decisions.

Manuscript received 2 June 2004; revised 21 September 2004; accepted 21 September 2004. Corresponding Editor: M. Fortin. For reprints of this Special Feature, see footnote 1, p. 1965.

${ }^{3}$ E-mail: markab@unimelb.edu.au
In the first part of this paper, we outline briefly the broad conceptual frameworks for linking species with their landscapes, namely habitat models and spatial population models, and examine how they deal with uncertainty. In the second part, we explore conceptual responses to the more difficult issue of managing multiple species, and how these concepts are translated into practical management tools. Last, we evaluate syntheses emerging in practical applications, how they are used to conserve species at a landscape scale, and how they deal with uncertainty.

\section{Linking Single Species to a Landscape}

In broad terms, landscape managers create conceptual and quantitative models to simplify problems and guide decisions, usually employing a specific set of skills that result from training and context. A consequence is that the choice of a kind of model (here termed the "modeling frame") brings with it an unacknowledged set of biases and assumptions. Landscape ecology focuses on the link between the spatial pattern of a landscape and the dynamics of the species it supports. There are many ways to explore and characterize this link. Commonly, the first step is to acquire knowledge about the link through experiment or field observation. To achieve this, landscape modelers need to work with field ecologists to develop a sense of the scale and context of practical problems. Models can then be developed, often focusing on one species at a time. These are usually habitat models or spatially explicit population models. The following section outlines the essential features of these modeling approaches, the conventions they have adopted for representing 
TABLE 1. Habitat modeling methods arranged by their demands for data (after Elith and Burgman 2003).

\begin{tabular}{|c|c|c|}
\hline Type of habitat model & Data & References \\
\hline Habitat suitability index & Map(s) of variables and experts & $\begin{array}{l}\text { U.S. Fish and Wildlife Service (1980), Burg- } \\
\text { man et al. (2001) }\end{array}$ \\
\hline $\begin{array}{l}\text { Minimum convex polygons, al- } \\
\text { pha hulls, kernels }\end{array}$ & Locations only & Ostro et al. (1999), Burgman and Fox (2003) \\
\hline $\begin{array}{l}\text { Climate envelopes, multivariate } \\
\text { distance methods }\end{array}$ & Locations and maps of variables & $\begin{array}{l}\text { Nix (1986), Carpenter et al. (1993), Hirzel et } \\
\text { al. (2001) }\end{array}$ \\
\hline Resource selection functions & $\begin{array}{l}\text { Locations, random (available) loca- } \\
\text { tions, and maps of variables }\end{array}$ & Manly et al. (2002) \\
\hline $\begin{array}{l}\text { Generalized linear models } \\
\text { (GLMs; logistic regression), } \\
\text { generalized additive models } \\
\text { (GAMs), canonical correlation } \\
\text { analysis }\end{array}$ & $\begin{array}{l}\text { Presence/absence (where absence is } \\
\text { unused locations or pseudo-ab- } \\
\text { sence) and maps of variables }\end{array}$ & $\begin{array}{l}\text { McCullagh and Nelder (1989), Hastie and Tib- } \\
\text { shriani (1990), Austin (2002), Zaniewski et } \\
\text { al. (2002), ter Braak (1986) }\end{array}$ \\
\hline $\begin{array}{l}\text { GLMs or GAMs (Poisson re- } \\
\text { gression) }\end{array}$ & Abundance and maps of variables & $\begin{array}{l}\text { McCullagh and Nelder (1989), Hastie and Tib- } \\
\text { shriani (1990) }\end{array}$ \\
\hline $\begin{array}{l}\text { Decision trees, multivariate } \\
\text { adaptive regression splines } \\
\text { (MARS), machine learning } \\
\text { methods (e.g., neural net- } \\
\text { works, genetic algorithms) }\end{array}$ & $\begin{array}{l}\text { In theory, many of these can be } \\
\text { adapted to any data. }\end{array}$ & $\begin{array}{l}\text { Breiman et al. (1984), Stockwell and Peters } \\
\text { (1999), Moisen and Frescino (2002) }\end{array}$ \\
\hline
\end{tabular}

uncertainty, and how the choice of a modeling frame may affect landscape management decisions.

\section{Habitat models}

Habitat models link the distribution of a species directly to environmental variables, taking on a landscape context when mapped in geographic space. Habitat modeling methods suit a variety of data, contexts, and skills. They include expert habitat suitability indices,
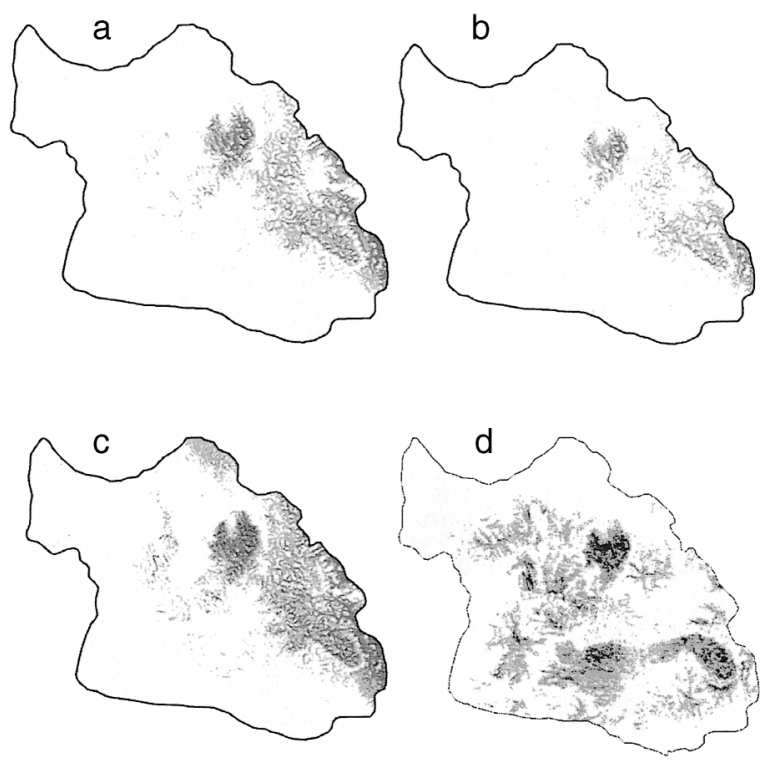

FIG. 1. Habitat models for Leptospermum grandifolium in Central Highlands, Victoria, Australia. (a) An "average" habitat model: a Bayesian model average (BMA) prediction for the habitat of Leptospermum grandifolium. (b) Upper and (c) lower $95 \%$ confidence intervals for the predicted probabilities based on a generalized linear model. (d) A habitat model based on DOMAIN, a multivariate distance method (Carpenter et al. 1993). envelope methods, multivariate and statistical models, and machine learning methods (Table 1). All can provide predictions of species distributions across a landscape, if the necessary data are available in a spatial form at an appropriate scale. Fig. 1a provides an example of a statistical model for a rare plant in southern Australia, based on presence-absence records and spatial environmental data (Elith 2000, Elith and Burgman 2003). Such models are used to guide biological surveys, design reserves and set resource management priorities.

Habitat maps usually are presented, used, and evaluated as if they were certain. In reality, there are numerous sources of uncertainty. For instance, model structure (choice of relevant variables, response shapes, methods for combining and weighting variables and accounting for spatial autocorrelation) is uncertain. Habitat models are sensitive to uncertainty in the underlying data layers and to the number, bias, accuracy, and representativeness of species records. Disturbance and other temporal dynamics make habitat maps uncertain. Most habitat maps take a static view of the relationship between a species and its environment, ignoring changes over time with ecological succession and disturbance. Maps are empirical and based on correlations and do not easily include causality. All of these sources of uncertainty, and others, are present in most habitat maps and should be recognized if we are to identify problems, correct errors and account for the uncertainty in predictions.

Elith et al. (2002) outlined a classification of uncertainties in habitat models. At the highest level, it distinguished between epistemic uncertainty (uncertainty in knowledge about facts) and linguistic uncertainty (uncertainty based on language). It recognized measurement error, bias, natural variation, model uncertainty, and subjective uncertainty as forms of epistemic 
TABLE 2. Spatial population modeling methods.

\begin{tabular}{|c|c|c|}
\hline Type of model & Data & References \\
\hline $\begin{array}{l}\text { Stochastic patch occupancy } \\
\text { models }\end{array}$ & $\begin{array}{l}\text { Patch structure, occupancy, recolonization, and } \\
\text { extinction rates }\end{array}$ & $\begin{array}{l}\text { Hanski (1994), Ovaskainen and } \\
\text { Hanski (2004), Moilanen (2004) }\end{array}$ \\
\hline Frequency (population) model & $\begin{array}{l}\text { Patch structure, population sizes, dispersal, fe- } \\
\text { cundity, survival, carrying capacity, levels } \\
\text { of variation }\end{array}$ & $\begin{array}{l}\text { Akçakaya and Ferson (1992), Ak- } \\
\text { çakaya (2001) }\end{array}$ \\
\hline Cellular automata & $\begin{array}{l}\text { Grid-based environmental data, dispersal char- } \\
\text { acteristics, carrying capacity }\end{array}$ & $\begin{array}{l}\text { Hogeweg (1988), Gaylord and } \\
\text { Nishidate (1996) }\end{array}$ \\
\hline $\begin{array}{l}\text { Continuous habitat quality meta- } \\
\text { population model }\end{array}$ & $\begin{array}{l}\text { Each cell has habitat quality that affects ex- } \\
\text { tinction and colonization rates. }\end{array}$ & $\mathrm{Gu}$ et al. (2002) \\
\hline Agent-based model & $\begin{array}{l}\text { Grid-based environmental data, behavioral } \\
\text { rules }\end{array}$ & Topping et al. (2003) \\
\hline Individual-based model & $\begin{array}{l}\text { Distributions of individuals, high-resolution } \\
\text { habitat suitability data, behavioral rules }\end{array}$ & $\begin{array}{l}\text { DeAngelis and Gross (1992), } \\
\text { Grimm (1999), Wiegand et al. } \\
(2003)\end{array}$ \\
\hline
\end{tabular}

uncertainty. Linguistic sources included vagueness (nature and language have gradual boundaries), ambiguity (words have more than one meaning) and underspecificity (unwanted generality in data).

Many habitat modeling methods, such as climate and geographic envelopes, have no formal means of representing uncertainty. Some methods are available to deal with uncertainty explicitly, but different methods reflect very different aspects. For instance, subjective and linguistic uncertainties may be represented in habitat suitability maps with fuzzy numbers (Burgman et al. 2001). In contrast, parameter uncertainty in statistical models may be represented with confidence intervals. Fig. $1 \mathrm{~b}$ and $\mathrm{c}$ show the $95 \%$ confidence intervals for the "best estimate" of a regression model. The bounds encapsulate parameter uncertainty and some of the uncertainties in the input data. Often, several alternative habitat models are plausible (e.g., Wintle et al. 2004). Model uncertainty may be represented by intervals that encompass several statistical models (Burnham and Anderson 2002) or reduced by using robust methods for model building (e.g., lasso, ridge regression, boosting; see Hastie et al. 2001). Bias and imprecision may be estimated by evaluating maps with new field data (Elith and Burgman 2003) or explored by simulating likely errors. Established methods characterize how uncertainty propagates through models (e.g., Heuvelink 1998). Whilst there are many techniques for exploring, characterizing and reducing uncertainty, most modelers fail to use any of them. We suggest that the only way to broaden our understanding of error and uncertainty and its impact on planning decisions is to incorporate analyses of uncertainty in modeling routinely.

Further, the decision to use a particular modeling frame brings with it inherent uncertainties. For instance, envelope methods based on climate variables tend to overpredict habitat. Geographic envelopes based on small samples tend to underpredict habitat (Burgman and Fox 2003). Models that do not incorporate complex responses to environments, interactions, or competition may be ecologically unrealistic
(Leathwick and Austin 2001, Austin 2002). We add modeling frame uncertainty to Elith et al.'s (2002) taxonomy, a form of uncertainty in which the choice of a modeling frame leads us to ignore a subset of the full suite of epistemic and linguistic uncertainties.

The choice of a habitat modeling frame is usually determined by available data and relevant skills. Rarely is more than one frame applied, even though predictions may be substantially different (e.g., Thuiller 2003). Thus, Fig. 1d represents a different, plausible prediction for the distribution for the rare plant based on multivariate distances, clearly outside the $95 \%$ confidence intervals of the statistical model. The only way to explore the impact of this kind of uncertainty is to try different modeling frames. If the results lead to different management decisions, the planner should explore the biological basis for the modeling frames, or choose an option that gives a reasonable outcome, irrespective of which habitat model is right. We also suggest that there should be a strong imperative for modelers to understand and report the tendencies and likely shortcomings of the modeling frame that they use, rather than publish results that imply that their preferred method is best and free of biases and errors. All models are false, and understanding their strengths and weaknesses will encourage informed use.

\section{Spatial population models}

Most habitat maps link presence or abundance to environmental data but, as Van Horne (1983) pointed out, the links between habitat occupancy, density and demographic success are not necessarily close. Spatial population models provide a bridge between habitat maps and the demography and ecology of a species (Fahrig 2003, in press).

Spatial population models encompass multiple modeling frames. These include incidence functions, stochastic patch occupancy models, frequency models, agent-based models, cellular automata, and individual based models (see Table 2 for references and examples). Metapopulation models assume more or less discrete local populations that interact by migration and

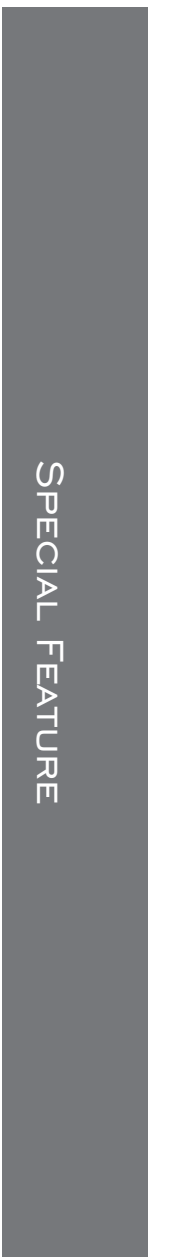


a

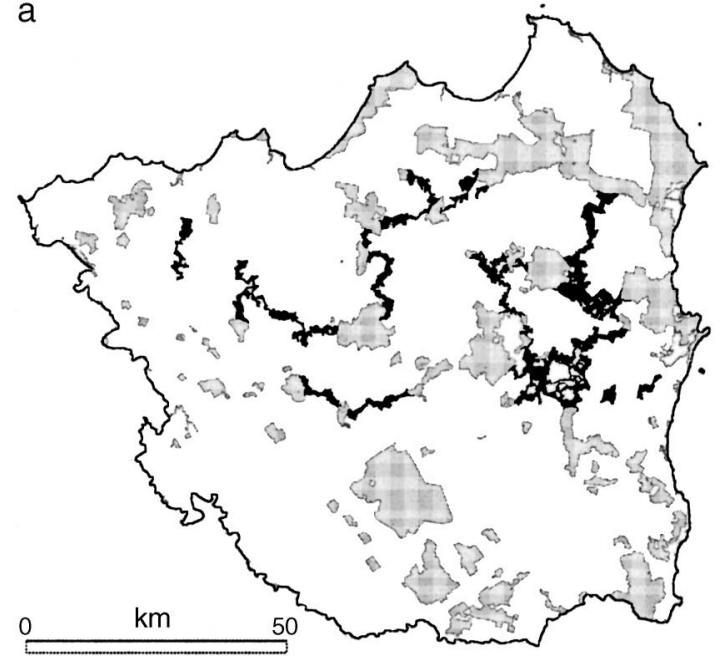

b

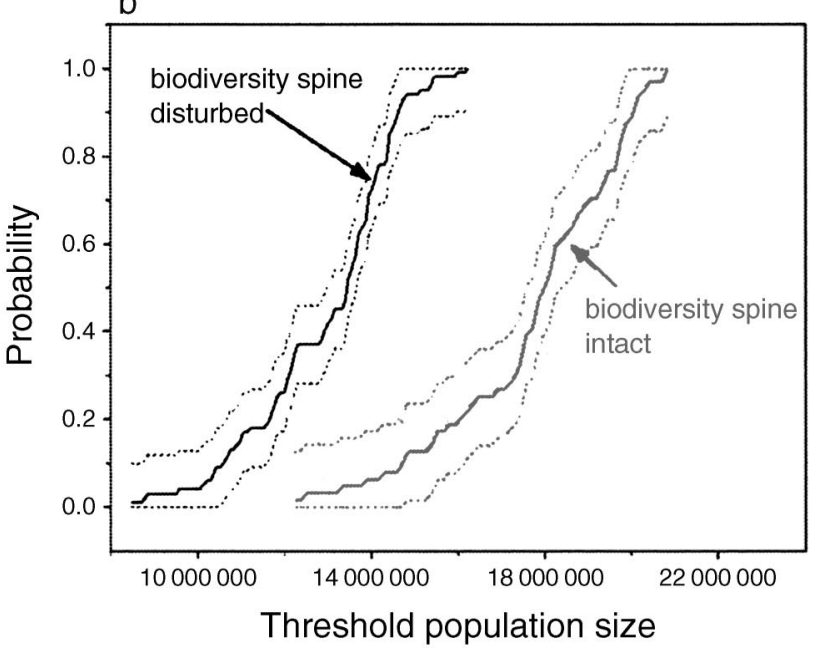

FIG. 2. (a) The "biodiversity spine" (black), a planning option for forest destined for harvesting and plantation conversion in northeast Tasmania. The spine was designed around the idea of maintaining a spatial pattern that would facilitate dispersal and a source of individuals for recolonization of disturbed patches in a forested landscape. It forms links with existing reserves (gray). Biodiversity spines will be disturbed by forest operations but are intended to be managed for flora and fauna values more intensively than the remaining landscape. (b) The probability of decline of Simson's stag beetle (Hoplogonus simsoni) in northeast Tasmania, with and without the biodiversity spine shown in (a). The lines are the cumulative probabilities of falling below the specified threshold population size at least once in the next 100 years. The dotted lines show $95 \%$ confidence intervals for the risk curves (Akçakaya 2001).

gene flow (Hanski and Gaggiotti 2004). All are driven by some kind of spatial representation of a species' habitat. However, the ways the models use spatial habitat information are very different. Some incidence functions and frequency models simplify the landscape into habitat, nonhabitat, and dispersal pathways. For instance, Akçakaya and Ferson (1992, Akçakaya 2001) developed a spatial algorithm to interpret the size and location of subpopulations and the connections between them, based on a habitat quality threshold and neighborhood size. Thus, patch size and connections may be conditioned by knowledge of a species' behavior, social structure, and dispersal ability. In contrast, most cellular automata and individual-based models use spatial environmental data or habitat models more directly. For example, Gu et al. (2002) developed a spatial incidence function metapopulation model that used habitat maps, regional (spatially autocorrelated) disturbance, dispersal, connectivity, and local extinctions.

Spatial population models deal explicitly with several aspects of uncertainty. Population models typically include natural variation with time-dependent model parameters. Parameter uncertainty may be incorporated in random samples of initial conditions. Many frameworks model spatially explicit disturbances and changes in habitat quality over time (Possingham 1996, Akçakaya et al. 2004). The uncertain outcomes of alternative management options can be explored by representing them as different model structures and assumptions. The importance of changes in parameters may be evaluated by comparing model outcomes with those that result from models that are unchanged, the usual focus of formal sensitivity analysis. For example, Fig. 2a shows a planning option for forests in an area of northeast Tasmania. The biodiversity spine is a planning concept based on landscape-planning principles. The efficacy of this option in reducing the risk of population decline for Simson's Stag Beetle was evaluated with a frequency-based metapopulation model (Fig. 2b). A range of such options may be ranked in terms of costs and benefits.

Parameter uncertainty alone may be large enough to affect decisions based on population models (Taylor 1995, Beissinger and Westphal 1998, Ludwig 1999, Reed et al. 2002). The choice of a population dynamic modeling frame carries with it additional embedded assumptions and simplifications, many of which are not questioned closely in routine applications because they are conventionally acceptable (cf., Brigham and Thomson 2003). Building models in different frames and examining the consequences will test the importance of these assumptions. For example, Mooij and DeAngelis (2003) explored the propagation of uncertainty in animal dispersal models in three modeling frames. They concluded that building ecological realism into complex models provides insurance against compounding errors. In addition to simulation approaches, there are likely to be theoretical and analytical solutions to the problem of assessing the errors associated with a model frame and this work would represent an exciting new research direction.

Even within a given modeling frame, usually there are alternative plausible models. Structural (model) un- 
TABLE 3. Landscape pattern models.

\begin{tabular}{|c|c|c|c|}
\hline $\begin{array}{l}\text { Type of landscape } \\
\text { pattern model }\end{array}$ & Data & Ecological considerations & References \\
\hline Island & $\begin{array}{l}\text { habitat/nonhabitat (for } \\
\text { all species) }\end{array}$ & $\begin{array}{l}\text { Sharp discontinuities, uninhabitable } \\
\text { matrix, habitat is static and iden- } \\
\text { tical for all species }\end{array}$ & $\begin{array}{l}\text { MacArthur and Wilson } \\
\text { (1967), Rosenzweig } \\
\text { (1995) }\end{array}$ \\
\hline Patch-matrix-corridor & $\begin{array}{l}\text { habitat/nonhabitat, dis- } \\
\text { persal pathways (for } \\
\text { all species) }\end{array}$ & $\begin{array}{l}\text { Sharp discontinuities, uninhabitable } \\
\text { matrix, habitat is static and iden- } \\
\text { tical for all species }\end{array}$ & Forman (1995) \\
\hline Habitat variegation & $\begin{array}{l}\text { grades of habitat suit- } \\
\text { ability, dispersal path- } \\
\text { ways }\end{array}$ & $\begin{array}{l}\text { Habitat is static and identical for all } \\
\text { species. }\end{array}$ & $\begin{array}{l}\text { McIntyre and Hobbs } \\
\text { (1999) }\end{array}$ \\
\hline Gradient concept & $\begin{array}{l}\text { environmental data, } \\
\text { knowledge of species } \\
\text { response to environ- } \\
\text { ment }\end{array}$ & $\begin{array}{l}\text { Species respond to environment as } \\
\text { pattern gradients at different in- } \\
\text { tensities (resolutions). }\end{array}$ & $\begin{array}{l}\text { McGarigal and Cushman } \\
\text { (2005) }\end{array}$ \\
\hline Environmental domains & $\begin{array}{l}\text { ecologically relevant en- } \\
\text { vironmental variables }\end{array}$ & $\begin{array}{l}\text { Habitat is determined by defined } \\
\text { combinations of environmental } \\
\text { drivers. }\end{array}$ & Leathwick et al. (2003) \\
\hline
\end{tabular}

certainty is rarely considered (cf., Pascual et al. 1997). They can be evaluated by changing model structures and dependencies, re-estimating parameters and reassessing management options. If alternative structures lead to different decisions, then landscape planners may choose among or average over alternatives (e.g., Fig. 1a), or take decisions that lead to acceptable outcomes, irrespective of which model is correct.

While the potential for relatively comprehensive examination of uncertainty exists in most population modeling frames, in many applications, such analyses are cursory or entirely absent. For instance, spatial population models do not account for the range of uncertainties in the underlying habitat maps outlined above. Until recently, most have ignored temporal habitat dynamics, interactions between multiple species and correlations in environmental conditions between spatially separate patches of habitat. Population modeling would be strengthened by new research on these issues.

Like habitat models, the choice of a modeling frame should not depend on the availability of relevant skills but in practice, it often does. Perhaps the most difficult issue of all is that spatial population models treat single species. Few applications support analyses of multiple interacting species in dynamic landscapes. Spatial population models provide managers with a tool for exploring the trade-offs and assumptions surrounding management alternatives. Their detail and spatial scale are flexible and can be modified to suit case-specific questions. However, as long as they remain focused on single species, their utility will remain limited to solving iconic and economically important problems. Advances in methods for considering multiple species would be particularly useful.

\section{Linking Many Species to a LANDSCAPE Through PATTERN ANALYSIS}

Forman's (1995) concept of landscape pattern was an attempt to reconcile the absence of direct information about the majority of species with the need to make decisions about how to manage landscapes. Landscape pattern models characterize the size, shape and arrangement of elements in a landscape and relate them to environmental variables that maintain species diversity and ecological processes. They include the island model (MacArthur and Wilson 1967; see review by Haila 2002), Forman's (1995) patch-corridor-matrix mosaic, and models that focus more on gradients such as habitat variegation, the gradient concept and environmental domains (Table 3). Landscape patterns defined by these models may be quantified with pattern indices that measure heterogeneity, spatial contagion, fractal dimension, connectivity and so on (e.g., O'Neill et al. 1988, Li and Reynolds 1994), although attributes relevant for a specific question, and the scale at which they should be evaluated, need to be defined in terms of the organisms' characteristics (Lindenmayer et al. 2002, Moilanen and Nieminen 2002, With 2004, McGarigal and Cushman 2005).

In general, landscape pattern models ignore uncertainty. Indices of spatial pattern are uncertain because habitat quality is heterogeneous within patches, and gradients vary with different stages of an organism's life history, with ecological succession and following disturbance (Whittaker et al. 1973, Austin 1999, Fox and Fox 2000). Different species use landscapes differently and at different scales, making it difficult to abstract landscape properties in a way that makes sense for all, or even for most, species (Wiens 1994, Manning et al. 2004). For example, Fig. 3 illustrates habitat patterns for a bird, a mammal, and a beetle in northeast Tasmania: species that use the landscape at different spatial scales. Some of these uncertainties are quantitative and others are qualitative and subjective, making it difficult to represent them all with a single reliability measure. However, the ecological reasons for choosing an index often are not provided, few measures are used consistently in different studies, many are scale dependent and they provide no measures of uncertainty 


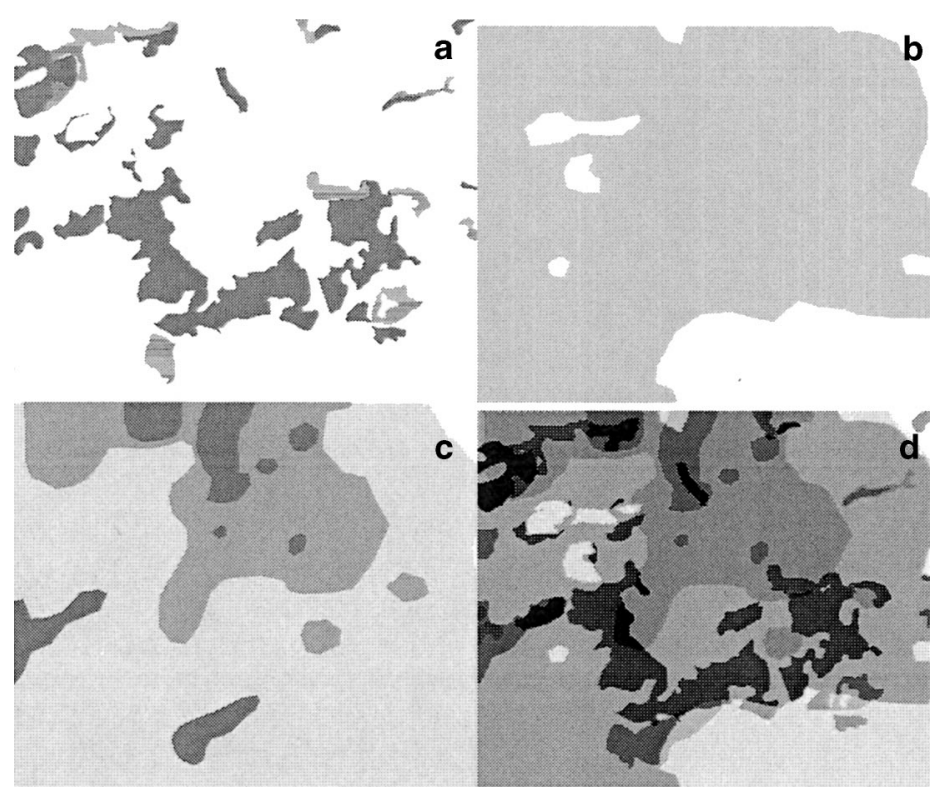

FIG. 3. Habitat maps for three species: (a) Yellow-tailed Black Cockatoo (Calptorhynchus funereus), (b) spotted-tailed quoll (Dasyurus maculatus), and (c) Simson's stag beetle (Hoplogonus simsoni); and (d) a landscape contour map, based on the habitat maps for the same three species. Contours are constructed by overlaying habitat suitability maps for individual species. Darker regions are relatively suitable for many species. The maps are a $4 \times 3.5 \mathrm{~km}$ section of the region in Fig. 2, in northeast Tasmania.

(Cale and Hobbs 1994, Moilanen and Hanski 2001, Dungan et al. 2002, Lindenmayer et al. 2002, Wu 2004).

One problem with several of the landscape pattern methods is that they present maps with hard boundaries. In reality, transition zones in nature are not usually sharp. One way of dealing with uncertainty in boundaries is to avoid creating them, instead viewing patterns in biodiversity as a continuum (Ferrier 2002, Faith 2003, McGarigal and Cushman 2005). Fuzzy set theory can address intermediate classes and indeterminate boundaries in maps (Arnot et al. 2004). Nevertheless, uncertainties in pattern maps usually are not communicated (cf., Elith et al. 2002) and rarely contribute to decision making.

The choice of a modeling frame within which to represent landscape pattern carries with it many assumptions about the grain and extent of the landscape and the ways in which species respond to landscape management (Dungan et al. 2002, McGarigal and Cushman 2005). Like habitat and population models, the choice of the modeling frame should not depend on conventional acceptability or the availability of relevant skills but in practice, it often does. The importance of the choice may be explored by characterizing a landscape within two or more frames and examining if the choice makes a difference to management decisions. If it does, the landscape planner is obliged to explore further the ecological foundation for the choice, or to make decisions that deliver acceptable outcomes, irrespective of the choice of a frame.

\section{Managing Landscapes}

Landscape managers are aware that explicit single and multiple species models do not deal explicitly with most things of value in a landscape. Managers make decisions, despite the complexities of ecosystems. These circumstances have precipitated a scramble of ideas to assist managers to make decisions with at least some ecological support. Several of these approaches are outlined below, each of which carries assumptions about habitat, population dynamics, and ecological responses to change.

Ideas about landscape pattern have contributed to strategies for management. The island model suggests reserves close together are better than reserves far apart, and the patch-corridor-matrix model further suggests that reserves connected by a corridor are better than isolated reserves (see reviews and critiques by Gilbert 1980, Burgman et al. 1988, Simberloff 1988, Doak and Mills 1994, Haila 2002, Manning et al. 2004). However, it is difficult to find simple guidelines built on these concepts that result in effective conservation strategies in a variety of circumstances for a range of species. Empirical research shows that the beneficial effects of corridors depend on their width, length, location in the landscape, the extent to which the matrix is used by species of interest, and the type and pattern of land use in the matrix (Hobbs 1992, Lindenmayer and Possingham 1996, Rosenberg et al. 1997, Beier and Noss 1998, Bennett 1998). On the negative side, corridors may exacerbate the spread of weeds, pest animals, diseases, and fires, and connect high-quality habitat patches to population "sinks" (Harrison and Bruna 2000).

The island model led to the premise that speciespoor, small, habitat patches support subsets of assemblages from larger, species-rich patches, termed nested subset theory (see Table 3 for references; see Fischer and Lindenmayer 2002). This theory leads to a focus on large patches, at the expense of smaller and more isolated patches. Nested subset theory and island the- 
ory focus on collective measures (assemblage composition and species diversity respectively), ignoring species-specific information on dispersal, interactions, recolonization, and the ability of populations to recover from disturbance.

A common way to manage landscapes is to manipulate the spatial pattern. For example, the planning option in Fig. 2 was devised by forest managers to conform with Forman's (1995) patch-matrix-corridor model. Landscapes that retain corridors are assumed to be more likely to maintain species because subpopulations can recolonize empty habitat patches and exchange individuals and genes (Brown and Kodric-Brown 1977, Haddad and Baum 1999). Reserves in Fig. 2 were considered to be refugia for many species. The "matrix" of relatively unsuitable habitat included areas destined for harvesting and regeneration or conversion to plantations, along with patches that were not scheduled for harvesting. The spines provided connections, corridors, and dispersal pathways between patches.

Another way to manage landscapes is to manipulate spatial and temporal disturbances to mimic those of "natural" disturbance regimes (e.g., Hunter 1993, Attiwill 1994). This approach has many of the same assumptions and uncertainties as the landscape pattern models outlined above but it adds a temporal dimension to account for dynamic change. Spatial dynamics such as disturbance and vegetation succession have been included in spatial population models by making patch qualities and carrying capacities change over time (Possingham and Davies 1995, Akçakaya 2001). Such models have been further developed to include dynamics such as fire explicitly (e.g., see examples in Akçakaya et al. 2004). Uncertainty arises because the characteristics of a natural disturbance regime can be difficult to estimate and fire regimes are difficult to manage (Burgman 1996, Richards et al. 1999).

Focal species are an attempt to provide landscape managers with a direct link between landscape patterns and the ecology of species. A "focal" species, the most susceptible, is identified for each landscape attribute such as patch size, connectedness and disturbance intensity and frequency. It is the species that is likely to experience the largest increase in extinction risk when the attribute changes. Together, focal species have ecological requirements that define the attributes (spatial patterns) that meet the needs of the biota (Lambeck 1997). This definition uses the concept of "umbrella" species, whose protection will result in the protection of most other species (see Fleishman et al. 2000). While it is difficult to know which species are most sensitive to each attribute (e.g., Brooker and Brooker 2002; see Lindenmayer and Fischer 2003) and empirical evidence is equivocal (Andelman and Fagan 2000), the method provides a more concrete template for designing minimal landscape requirements for species persistence than using spatial pattern alone. Assumptions could be explored with empirical data and population models.
Habitat models provide decision support for single species, whereas most real contexts demand judgments for many species. The landscape-contour model is a different attempt to link the ecological attributes of many species to landscape patterns. Landscape contours are composed of overlays of habitat suitability contours for different species (see Fischer et al. 2004). The spatial grain (Dungan et al. 2002) at which species respond to their environment is reflected in different contour densities (Wiens 1995). Fig. 3d provides an example of a landscape-contour model for the three species habitat models in Fig. 3a-c. As such, it represents a kind of a spatial average over species.

A common approach to managing biodiversity is to protect species-rich hotspots (Mittermeier et al. 1998) and other areas that contain unique assemblages of plants and animals. Reserve design algorithms seek comprehensive reserve systems, those that include a complete array of known biodiversity (Pressey 1994, Pressey and Cowling 2001). "Adequate" reserves aim to support viable populations. Spatial population models and habitat models have been used to evaluate reserve design options (e.g., Armbruster and Lande 1993, Moilanen and Cabeza 2002). Faith et al. (2003) described "biodiversity viability analysis" in which they estimated gains and losses in persistence of all species. Desmet et al. (2002) addressed the need to design reserves to account for spatial and evolutionary processes.

Because there are many species, and few data on most of them, it is impossible to model a substantial or representative set of species. This problem prompted Ferrier et al. (2002) to develop generalized dissimilarity modeling (GDM) to model the collective properties of the biota through the compositional dissimilarity (the $\beta$ and $\gamma$ diversity) of sites. GDM combines biotic samples and environmental data in a matrix regressionbased approach to predict compositional dissimilarities between grid cells. Predictions from GDM can be used to guide environmental classifications and to set priorities for conservation areas (Ferrier 2002). The approach is particularly useful in highly diverse, relatively data-poor regions, going beyond a few flagship taxa to a more comprehensive consideration of the biota.

The gaps between spatial population models and landscape models are apparent to managers involved in day-to-day decision making. Landscape models such as Forman's patch-corridor-matrix model lack explicit ecological support. Habitat and spatial population models provide information on only one or a few species. These concerns have led to the development of many of the innovations outlined above. However, there is no explicit recognition of uncertainty in corridor design, nested subsets, disturbance management, focal species, landscape contours, reserve design algorithms, or generalized dissimilarity modeling. Thus, even though some inroads have been made into modeling

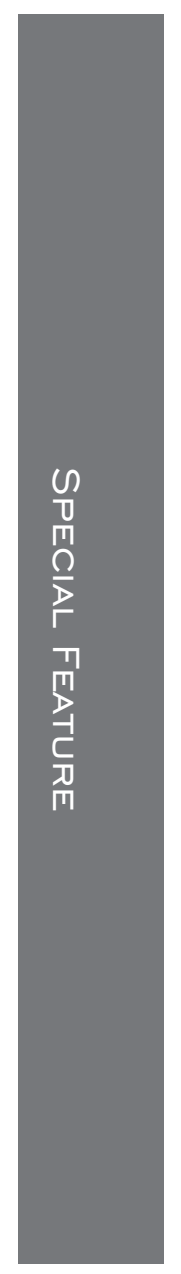


uncertainty in habitat models, spatial population models and landscape pattern models, these developments have not yet found their way into new, pragmatic management tools. And like the development of modeling frames for habitats, populations and landscapes, the choice of a landscape management model from among those outlined above usually is determined by convention and available skills. Decisions in many contexts will be sensitive to the choice, making it necessary for the planner to justify the choice on ecological grounds or to make decisions that give reasonable outcomes, no matter which frame is adopted.

\section{DISCUSSION}

Uncertainty is pervasive in all levels of landscape management for conservation. The importance of uncertainty depends on the context of a decision and increases with larger landscapes and longer time horizons. Yet many forms of uncertainty are not acknowledged in the models that support decisions. In some cases, uncertainty is ignored altogether. One of the most important and least recognized forms is the choice of a modeling frame. It exists at all operational levels and at all scales of ecological resolution, from single-species habitat modeling to landscape management. The question then arises, how can pervasive and unacknowledged uncertainty be embraced in landscape management for conservation?

Uncertainties may be assessed through careful evaluation of model predictions. Models are useful that predict accurately and precisely at a scale that makes operational sense. Monitoring can track the consequences of management decisions, so that the weight given to predictions from a model that is routinely wrong declines as experience accumulates. A more explicit approach is to adopt procedures that account for as many forms of uncertainty as possible (such as error propagation and sensitivity analyses) and to use several modeling frames and examine if the choice makes a difference to management decisions. If it does, the landscape planner may explore further the ecological and statistical foundation for the choice.

In general, decision strategies for landscape management try to maximize performance (e.g., Weitzman 1998, Possingham et al. 2002a, b, Westphal and Possingham 2003). An alternative path, to which we alluded several times above, is to make decisions that maximize the chance of a tolerable outcome, despite what is unknown and irrespective of the choice of a frame. There is a firm theoretical foundation for this strategy. Decision strategies should seek robust outcomes that are acceptable to the stakeholders who carry the burden of the risks (Ben-Haim 2001, Burgman 2005). Landscape planners should not focus on finding a true model, but rather should explore models and modeling frames that lead them to consider robust, satisfactory alternatives.
A model structure and its level of detail will be determined by the kind of decision one needs to make. For example, a very simple model may be sufficient, even when data are abundant, if it can be shown that the simple model subsumes or bounds more complex interpretations of the data or if the decision is invariant to the model detail. If the decision context is known, then decision theory (Ben-Haim 2001, Possingham et al. 2002b) may provide means for combining evidence and arbitrating between alternatives to maximize robustness to uncertainty.

Often, modelers feel compelled to try to make better predictions, without considering the context in which their predictions will be used. Good decision making probes uncertainty (Edwards and Fortin 2001), leading to a better understanding of the role uncertainty plays in managing a landscape. Better decisions may not necessarily depend on better models or more precise scientific predictions, but on a better understanding of the decision context and the social imperatives that drive it (Pielke 2003).

The model we use to represent landscapes affects the way we subsequently interpret the effects of change and look for options that mitigate risks. In the past, landscape management has been governed by either landscape pattern or the considerations of individual species. However, syntheses are emerging in applications. While there is some recognition of uncertainty in spatial pattern models, habitat models and spatial population models, it is little considered in the decision domain. Landscape managers are responsible for many species. The new challenge is to develop decision support systems in which ecologically-based, multi-species predictions are cast in a form that is useful for conservation managers and that provides information on uncertainty so that managers may make risk-based decisions. The foundations for these advances lie in decision theory (see Ben-Haim 2001) and research into robust decision making for multispecies management is urgently required.

\section{ACKNOWLEDGMENTS}

We thank Lenore Fahrig, Nicolas Ray, Atte Moilanen, Anurag Agrawal, Marie-Josée Fortin, and two anonymous reviewers for their comments on drafts of the manuscript. Jeff Meggs, Simon Grove, and others at Forestry Tasmania, which initiated the northeast Tasmanian project, supplied data and advice, and gave permission for us to use the data in Figs. 2 and 3 .

\section{Literature Cited}

Akçakaya, H. R. 2001. Linking population-level risk assessment with landscape and habitat models. Science of the Total Environment 274:283-291.

Akçakaya, H. R., M. Burgman, O. Kindvall, C. C. Wood, P. Sjogren-Gulve, J. Hatfield, and M. McCarthy, editors. 2004. Species conservation and management: case studies using RAMAS GIS. Oxford University Press, New York, New York, USA.

Akçakaya, H. R., and S. Ferson. 1992. RAMAS/space. Applied Biomathematics, Setauket, New York, USA. 
Andelman, S. J., and W. F. Fagan. 2000. Umbrellas and flagships: efficient conservation surrogates or expensive mistakes? Proceedings of the National Academy of Science (USA) 97:5954-5959.

Armbruster, P., and R. Lande. 1993. A population viability analysis for African elephant (Luxodonta africana): how big should reserves be? Conservation Biology 7:602-610.

Arnot, C., P. F. Fisher, R. Wadsworth, and J. Wellens. 2004. Landscape metrics with ecotones: pattern under uncertainty. Landscape Ecology 19:181-195.

Attiwill, P. M. 1994. The disturbance of forest ecosystems: the ecological basis for conservative management. Forest Ecology and Management 63:247-300.

Austin, M. P. 1999. A silent clash of paradigms: some inconsistencies in community ecology. Oikos 86:170-178.

Austin, M. P. 2002. Spatial prediction of species distribution: an interface between ecological theory and statistical modelling. Ecological Modelling 157:101-118.

Beier, P., and R. Noss. 1998. Do habitat corridors provide connectivity? Conservation Biology 12:1241-1252.

Beissenger, S. R., and M. I. Westpahl. 1998. One the use of demographic models of population viability in endangered species management. Journal of Wildlife Management 62 : 821-841

Ben-Haim, Y. 2001. Information-gap decision theory: decisions under severe uncertainty. Academic Press, San Diego, California, USA.

Bennett, A. F. 1998. Linkages in the landscape. The role of corridors and connectivity in wildlife conservation. IUCN Gland, Switzerland.

Breiman, L., J. H. Friedman, R. A. Olshen, and C. J. Stone. 1984. Classification and regression trees. Wadsworth International Group, Belmont, California, USA.

Brigham, C. A., and D. M. Thomson. 2003. Chapter 6: approaches to modeling population viability in plants: an overview. Pages 145-171 in C. A. Brigham and M. W Schwartz, editors. Population viability in plants. SpringerVerlag, New York, New York, USA.

Brooker, L., and M. Brooker. 2002. Dispersal and population dynamics of the Blue-breasted Fairy-wren, Malurus pulcherrimus, in fragmented habitat in the Western Australian wheatbelt. Wildlife Research 29:225-233.

Brown, J. H., and A. Kodric-Brown. 1977. Turnover rates in insular biogeography: effect of immigration on extinction. Ecology 58:445-449.

Burgman, M. A. 1996. Characterisation and delineation of eucalypt old-growth forest in Australia: a review. Forest Ecology and Management 83:149-161.

Burgman, M. A. 2005. Risks and decisions for conservation and environmental management. Cambridge University Press, Cambridge, UK.

Burgman, M. A., H. R. Akçakaya, and S. S. Loew. 1988. The use of extinction models for species conservation. Biological Conservation 43:9-25.

Burgman, M. A., D. R. Breininger, B. W. Duncan, and S. Ferson. 2001. Setting reliability bounds on habitat suitability indices. Ecological Applications 11:70-78.

Burgman, M. A., and J. Fox. 2003. Bias in species range estimates from minimum convex polygons: implications for conservation and options for improved planning. Animal Conservation 6:19-28.

Burnham, K. P., and D. R. Anderson. 2002. Model selection and multimodel inference: a practical information-theoretic approach. Second edition. Springer-Verlag, New York, New York, USA.

Cale, P. G., and R. J. Hobbs. 1994. Landscape heterogeneity indices: problems of scale and applicability, with particular reference to animal habitat description. Pacific Conservation Biology 1:183-193.
Carpenter, G., A. N. Gillison, and J. Winter. 1993. DOMAIN: a flexible modelling procedure for mapping potential distributions of plants and animals. Biodiversity and Conservation 2:667-680.

DeAngelis, D. L., and L. J. Gross, editors. 1992. Individualbased models and approaches in ecology. Chapman and Hall, London, UK.

Desmet, P. G., R. M. Cowling, A. G. Ellis, and R. L. Pressey. 2002. Integrating biosystematic data into conservation planning: persepectives from southern Africa's succulent Karoo. Systematic Biology 51:317-330.

Doak, D., and L. S. Mills. 1994. A useful role for theory in conservation. Ecology 75:615-626.

Dungan, J. L., J. N. Perry, M. R. T. Dale, P. Legendre, S. Citron-Pousty, M.-J. Fortin, A. Jakomulska, M. Miriti, and M. S. Rosenberg. 2002. A balanced view of scale in spatial statistical analysis. Ecography 25:626-640.

Edwards, G., and M.-J. Fortin. 2001. Cognitive view of spatial uncertainty. Pages 133-157 in M. Goodchild, M. Friedl, T. Case, and C. Hunsaker, editors. Spatial uncertainty in ecology. Implications for remote sensing and GIS applications. Springer-Verlag, New York, New York, USA.

Elith, J. 2000. Quantitative methods for modeling species habitat: comparative performance and an application to Australian plants. Pages 39-58 in S. Ferson and M. Burgman, editors. Quantitative methods in conservation biology. Springer-Verlag, Berlin, Germany.

Elith, J., and M. A. Burgman. 2003. Habitat models for population viability analysis. Pages 203-235 in C. A. Brigham and M. W. Schwartz, editors. Population viability in plants. Springer-Verlag, Heidelberg, Germany.

Elith, J., M. A. Burgman, and H. Regan. 2002. Mapping epistemic uncertainties and vague concepts in predictions of species distribution. Ecological Modelling 157:313-329.

Fahrig, L. 2003. Effects of habitat fragmentation on biodiversity. Annual Review of Ecology, Evolution and Systematics 34:487-515.

Fahrig, L. In press. Landscape heterogeneity and metapopulation dynamics. In J. Wu and R. Hobbs, editors. Key perspectives in landscape ecology. Cambridge University Press, Cambridge, UK.

Faith, D. P. 2003. Environmental diversity (ED) as surrogate information for species-level biodiversity. Ecography 26: 374-379.

Faith, D. P., G. Carter, G. Cassis, S. Ferrier, and L. Wilkie. 2003. Complementarity, biodiversity viability analysis, and policy-based algorithms for conservation. Environmental Science and Policy 6:311-328.

Ferrier, S. 2002. Mapping spatial pattern in biodiversity for regional conservation planning: where to from here? Systematic Biology 51:331-363.

Ferrier, S., M. Drielsma, G. Manion, and G. Watson. 2002. Extended statistical approaches to modelling spatial pattern in biodiversity: the north-east New South Wales experience. II. Community-level modelling. Biodiversity and Conservation 11:2309-2338.

Fischer, J., and D. B. Lindenmayer. 2002. Treating the nestedness temperature calculator as a black box can lead to false conclusions. Oikos 99:193-199.

Fischer, J., D. B. Lindenmayer, and I. Fazey. 2004. Appreciating ecological complexity: habitat contours as a conceptual landscape model. Conservation Biology 18(5): 1245-1253.

Fleishman, E., D. D. Murphy, and P. F. Brussard. 2000. A new method for selection of umbrella species for conservation planning. Ecological Applications 10:569-579.

Forman, R. T. 1995. Land mosaics. The ecology of landscapes and regions. Cambridge University Press, New York, New York, USA.

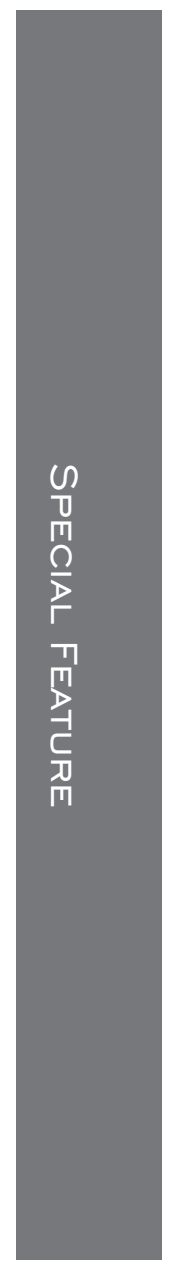


Forman, R. T., and M. Godron. 1986. Landscape ecology. Wiley and Sons, New York, New York, USA.

Fox, B. J., and M. D. Fox. 2000. Factors determining mammal species richness on habitat islands and isolates: habitat diversity, disturbance, species interactions and guild assembly rules. Global Ecology and Biogeography 9:19-37.

Gaylord, R. J., and K. Nishidate. 1996. Modeling nature: cellular automata simulations with Mathematica. SpringerVerlag, New York, New York, USA.

Gilbert, L. E. 1980. The equilibrium theory of island biogeography: fact or fiction? Journal of Biogeography 7:209235.

Grimm, V. 1999. Ten years of individual-based modelling in ecology: what have we learned and what could we learn in the future? Ecological Modelling 115:129-148.

Gu, W., R. Heikkilä, and I. Hanski. 2002. Estimating the consequences of habitat fragmentation on extinction risk in dynamic landscapes. Landscape Ecology 17:699-710.

Haddad, N. M., and K. A. Baum. 1999. An experimental test of corridor effects on butterfly densities. Ecological Applications 9:623-633.

Haila, Y. 2002. A conceptual genealogy of fragmentation research from island biogeography to landscape ecology. Ecological Applications 12:321-334.

Hanski, I. 1994. Patch occupancy dynamics in fragmented landscapes. Trends in Evolution and Ecology 9:131-134.

Hanski, I., and O. E. Gaggiotti. 2004. Metapopulation biology: past, present, and future. Pages 3-22 in I. Hanski and O. E. Gaggiotti, editors. Ecology, genetics, and evolution of metapopulations. Elsevier, Amsterdam, The Netherlands.

Hanski, I., and M. Gilpin. 1991. Metapopulation dynamics: brief history and conceptual domain. Biological Journal of the Linnean Society 42:3-16.

Harrison, S., and E. Bruna. 2000. Habitat fragmentation and large-scale conservation: what do we know for sure? Ecography 22:225-232.

Hastie, T., and R. Tibshirani. 1990. Generalized additive models. Chapman and Hall, London, UK.

Hastie, T., R. Tibshirani, and J. H. Friedman. 2001. The elements of statistical learning: data mining, inference, and prediction. Springer-Verlag, New York, New York, USA.

Heuvelink, G. B. M. 1998. Error propagation in environmental modelling with GIS. Taylor and Francis, London, UK.

Hirzel, A. H., V. Helfer, and F. Metral. 2001. Assessing habitat-suitability models with a virtual species. Ecological Modelling 145:111-121.

Hobbs, R. J. 1992. The role of corridors in conservation: solution or bandwagon? Trends in Ecology and Evolution 7:389-392.

Hobbs, R. J., and C. J. Yates. 2003. Impacts of ecosystem fragmentation on plant populations: generalising the idiosyncratic. Australian Journal of Botany 51:471-488.

Hogeweg, P. 1988. Cellular automata as a paradigm for ecological modeling. Applied Mathematics and Computing 27: $81-100$.

Hunter, M. L. 1993. Natural fire regimes as spatial models for managing boreal forests. Biological Conservation 65: $115-120$.

Lambeck, R. J. 1997. Focal species: a multi-species umbrella for nature conservation. Conservation Biology 11:849856.

Leathwick, J. R., and M. P. Austin. 2001. Competitive interactions between tree species in New Zealand's oldgrowth indigenous forests. Ecology 82:2560-2573.

Leathwick, J. R., J. M. Overton, and M. McLeod. 2003. An environmental domain classification of New Zealand and its use as a tool for biodiversity management. Conservation Biology 17:1612-1623.
Li, H., and J. F. Reynolds. 1994. A simulation experiment to quantify spatial heterogeneity in categorical maps. Ecology 75:2446-2455.

Lindenmayer, D. B., R. B. Cunningham, C. F. Donnelly, and R. Lesslie. 2002. On the use of landscape indices as ecological indicators in fragmented forests. Forest Ecology and Management 159:203-216.

Lindenmayer, D. B., and J. F. Fischer. 2003. The focal species approach: sound science or social hook. Landscape and Urban Planning 62:149-158.

Lindenmayer, D. B., and H. P. Possingham. 1996. Modeling the relationships between habitat connectivity, corridor design and wildlife conservation within intensively logged wood production forests of south-eastern Australia. Landscape Ecology 11:79-105.

Ludwig, D. 1999. Is it meaningful to estimate a probability of extinction? Ecology 80:293-310.

MacArthur, R. H., and E. O. Wilson. 1967. The theory of island biogeography. Princeton University Press, Princeton, New Jersey, USA.

Manly, B. F. J., L. L. McDonald, D. L. Thomas, T. L. McDonald, and W. P. Erickson. 2002. Resource selection by animals: statistical design and analysis for field studies. Second edition. Kluwer Academic Publishers, Dordrecht, The Netherlands.

Manning, A. D., D. B. Lindenmayer, and H. A. Nix. 2004. Continua and umwelt: alternative ways of viewing landscapes. Oikos 104:621-628.

McCullagh, P., and J. A. Nelder. 1989. Generalized linear models. Second edition. Chapman and Hall, London, UK.

McGarigal, K., and S. A. Cushman. 2005. The gradient concept of landscape structure. Pages 112-119 in J. A. Wiens and M. Moss, editors. Issues and perspectives in landscape ecology. Cambridge University Press, Cambridge, UK.

McIntyre, S., and R. Hobbs. 1999. A framework for conceptualizing human effects on landscapes and its relevance to management and research models. Conservation Biology 13:1282-1292.

Mittermeier, R. A., N. Myers, J. G. Thomsen, G. A. da Fonseca, and S. Oliveri. 1998. Biodiversity hotspots and major tropical wilderness areas: approaches to setting conservation priorities. Conservation Biology 12:516-520.

Moilanen, A. 2004. SPOMSIM software for stochastic patch occupancy models of metapopulation dynamics. Ecological Modelling 179(4):533-550.

Moilanen, A., and M. Cabeza. 2002. Single-species dynamic site selection. Ecological Applications 12:913-926.

Moilanen, A., and I. Hanski. 2001. On the use of connectivity measures in spatial ecology. Oikos 95:147-151.

Moilanen, A., and M. Nieminen. 2002. Simple connectivity measures in spatial ecology. Ecology 83:1131-1145.

Moisen, G. G., and T. S. Frescino. 2002. Comparing five modeling techniques for predicting forest characteristics. Ecological Modelling 157:209-225.

Mooij, W. M., and D. L. DeAngelis. 2003. Uncertainty in spatially explicit animal dispersal models. Ecological Applications 13:794-805.

Nix, H. 1986. A biogeographic analysis of Australian elapid snakes. Pages 4-15 in R. Longmore, editor. Atlas of elapid snakes of Australia. Australian Government Publishing Service, Canberra, Australia.

O’Neill, R. V., J. R. Krummel, R. H. Gardener, G. Sugihara, D. L. DeAngelis, B. T. Milne, M. G. Turne, B. Zysmunt, S. W. Christensen, V. H. Dale, and R. L. Graham. 1988. Indices of landscape pattern. Landscape Ecology 1:153162.

Ostro, L. E. T., T. P. Young, S. C. Silver, and F. W. Koontz. 1999. A geographic information system method for estimating home range size. Journal of Wildlife Management 63:748-755. 
Ovaskainen, O., and I. Hanski. 2004. Metapopulation dynamics in highly fragmented landscapes. Pages 73-104 in I. Hanski and O. E. Gaggiotti, editors. Ecology, genetics, and evolution of metapopulations. Elsevier, Amsterdam, The Netherlands.

Pascual, M., P. Kareiva, and R. Hilborn. 1997. The influence of model structure on conclusions about the variability and harvesting of Serengeti wildebeest. Conservation Biology 11:966-976.

Pielke, R. A.,Jr. 2003. The role of models in prediction for decision. Pages 111-135 in C. D. Canham, J. J. Cole, and W. K. Lauenroth, editors. Models in ecosystem science. Princeton University Press, Princeton, New Jersey, USA.

Possingham, H. P. 1996. Decision theory and biodiversity management: how to manage a metapopulation. Pages 391398 in R. B. Floyd, A. W. Sheppard, and P. J. De Barro, editors. Proceedings of the Nicholson Centenary Conference 1995. CSIRO Publishing, Canberra, Australia.

Possingham, H. P., S. J. Andelman, M. A. Burgman, R. A. Medellín, L. L. Master, and D. A. Keith. 2002a. Limits to the use of threatened species lists. Trends in Ecology and Evolution 17:503-507.

Possingham, H. P., and I. Davies. 1995. ALEX: a model for the viability analysis of spatially structured populations. Biological Conservation 73:143-150.

Possingham, H. P., D. B. Lindenmayer, and G. N. Tuck. $2002 b$. Decision theory for population viability analysis. Pages 470-489 in S. R. Beissinger and D. R. McCullough, editors. Population viability analysis. University of Chicago Press, Chicago, Illinois, USA.

Pressey, R. L. 1994. Ad hoc reservations: forward or backward steps in developing representative reserve systems. Conservation Biology 8:662-668.

Pressey, R., and R. M. Cowling. 2001. Reserve selection algorithms and the real world. Conservation Biology 15 275-277.

Reed, J. M., L. S. Mills, J. B. Dunning, E. S. Menges, K. S. McKelvey, R. Frye, S. R. Beissenger, M. Antett, and P. Miller. 2002. Emerging issues in population viability analysis. Conservation Biology 16:7-19.

Richards, S. A., H. P. Possingham, and J. Tizard. 1999. Optimal fire management for maintaining community diversity. Ecological Applications 9:880-892.

Rosenberg, D. K., B. R. Noon, and E. C. Meslow. 1997. Biological corridors: form, function and efficacy. BioScience 47:677-687.

Rosenzweig, M. L. 1995. Species diversity in space and time. Cambridge University Press, Cambridge, UK.

Simberloff, D. A. 1988. The contribution of population and community biology to conservation science. Annual Review of Ecology and Systematics 19:473-511.

Stockwell, D., and D. Peters. 1999. The GARP modelling system: problems and solutions to automated spatial pre- diction. International Journal of Geographic Information Science 13:143-158.

Taylor, B. L. 1995. The reliability of using population viability analysis for risk classification of species. Conservation Biology 9:551-558.

ter Braak, C. J. F. 1986. Canonical correspondence analysis: a new eigenvector technique for multivariate direct gradient analysis. Ecology 67:1167-1179.

Thuiller, W. 2003. BIOMOD_optimizing predictions of species distributions and projecting future shifts under global change. Global Change Biology 9:1353-1362.

Topping, C. J., T. S. Hansen, T. S. Jensen, J. U. Jepsen, F. Nikolajsen, and P. Odderskær. 2003. ALMaSS, an agentbased model for animals in temperate European landscapes. Ecological Modelling 167:65-82.

U.S. Fish and Wildlife Service. 1980. Habitat evaluation procedure. United States Fish and Wildlife Service. Ecological Services Manual No. 102. U.S. Government Printing Office, Washington, D.C., USA.

Van Horne, B. 1983. Density as a misleading indicator of habitat quality. Journal of Wildlife Management 47:893901.

Weitzman, M. 1998. The Noah's Ark problem. Econometrica 66: $1279-1298$.

Westphal, M., and H. P. Possingham. 2003. Applying a decision-theory framework to landscape planning for biodiversity: follow-up to Watson et al. Conservation Biology 17:327-329.

Whittaker, R. H., S. A. Levin, and R. B. Root. 1973. Niche, habitat and ecotope. American Naturalist 107:321-328.

Wiegand, T., F. Jeltsch, I. Hanski, and V. Grimm. 2003. Using pattern-oriented modeling for revealing hidden information: a key for reconciling ecological theory and application. Oikos 100:209-222.

Wiens, J. 1994. Habitat fragmentation: Island vs. landscape perspectives on bird conservation. Ibis 137:S97-S104.

Wiens, J. 1995. Landscape mosaics and ecological theory. Pages 1-26 in L. Hansson, L. Fahrig, and G. Merriam, editors. Landscape mosaics and ecological processes. Chapman and Hall, London, UK.

Wintle, B. A., M. M. McCarthy, R. P. Kavanagh, and M. A. Burgman. 2004. The use of Bayesian model averaging to better represent uncertainty in predictions derived from ecological models. Conservation Biology 17:1579-1590.

With, K. A. 2004. Metapopulation dynamics: perspectives from landscape ecology. Pages 23-44 in I. Hanski and O. E. Gaggiotti, editors. Ecology, genetics, and evolution of metapopulations. Elsevier, Amsterdam, The Netherlands.

Wu, J. 2004. Effects of changing scale on landscape pattern analysis: scaling relations. Landscape Ecology 19:125138.

Zaniewski, A. E., A. Lehmann, and J. M. Overton. 2002. Predicting species distribution using presence-only data: a case study of native New Zealand ferns. Ecological Modelling 157:261-280. 